\title{
Sleep Problems and Road Accidents
}

\author{
Miranda Nava Gabriel \\ Neurologist and Clinical Neurophysiologist, Chief of Neurology of the Hospital Center of the Presidential General Staff, Mexico
}

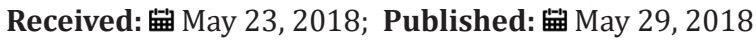

*Corresponding author: Gabriel Miranda Nava, Neurologist and Clinical Neurophysiologist, Attached to the Hospital Center of the Presidential General Staff, Master in Public Health, Doctor in Administration and Public policies, Mexico

\section{Background}

Traffic accidents are considered a public health problem and demonstrate several causative factors that include sleep deprivation, hours and hours of driving without rest, drugs with sedative action (anxiolytics, hypnotics, tricyclic antidepressants and antihistamines), sleep disorders (SAOS, narcolepsy), and alcohol consumption. There is a growing concern regarding Health and Safety in the Transport Sector with respect to drivers who, in their work performance, show a high risk of incidents due to drowsiness. Numerous studies show excessive sleepiness in public service drivers due to changes in the circadian rhythm and a high frequency of OSAS [1]. Excessive sleepiness and sleep deprivation are considered high risk factors for the development of suicidal ideation and behaviour.

\section{Excessive Drowsiness in the Work Performance of Drivers}

It is estimated that sleepiness is involved in $18 \%$ of all car accidents, and up to $25 \%$ in road accidents. A recent report estimates a frequency of $20.3 \%$ of "serious accidents" in the road transport industry caused by road accidents. Excessive somnolence [2] In a study published in Sleep Meds, excessive sleepiness plays an important role in the frequency of vehicular accidents on roads, with important consequences for drivers and passengers and with a high mortality rate. $3.2 \%$ of the total accidents occurred attributed to sleeping at the wheel and for somnolence, with mortality in $11.4 \%$ of the drivers. The foregoing contrasts with fatal results in $5.6 \%$ of accidents not associated with somnolence. The losses attributed to drowsiness occurred during the night or in the middle of the afternoon. The study confirmed the high mortality due to accidents related to somnolence. The results of the study show an association with circadian disorders due to the high frequency of accidents between 2-4 a.m. On the other hand, studies that evaluate sleep disorders in drivers show excessive daytime drowsiness caused by the change in the circadian rhythm and by a high frequency of OSAS [3].
Drivers with excessive daytime sleepiness have decreased levels of attention or concentration, and a reduced ability to respond to conditions that require immediate reactions. This variability in the state of alert can cause traffic accidents that are associated with high morbidity and mortality by event, in addition to important losses in infrastructure due to destruction of vehicles and material damage [4]. Although no driver is exempt from having a traffic accident due to drowsiness, bus drivers and taxi drivers show a high occupational risk [5].

Caso et al. [6] carried out a cross-sectional and descriptive study to determine the sleep characteristics of bus drivers, as well as their relationship with accidents that occurred on roads in Peru. The authors evaluated 166 drivers of the male gender with an average age $( \pm s$ ) of $44.2 \pm 8.7$ years. Caso et al. [6] applied a questionnaire regarding sleep patterns that was previously validated and the Epworth Sleepiness Scale. Of the total of the drivers, 74\% referred to work in the shift night. Of these, approximately $50 \%$ drove 5 to 7 nights per week and, the remaining drivers alternated driving 5-7 days during the day with 5-7 days at night. During the driving of the bus $75 \%$ of drivers reported experiencing fatigue, $45 \%$ blinking and $30 \%$ nodded. The drivers indicated that they experienced a greater sensation of fatigue when driving at dawn. One hundred and forty-five drivers (87\%) reported sleeping inside the bus when they were in the terminal or during their journey. The most frequent manoeuvre to reduce the feeling of fatigue when driving was to listen to music (34\%). $24 \%$ of drivers reported having had an accident or being close to having an accident due to fatigue. $27 \%$ of drivers showed scores compatible with excessive sleepiness according to the results of the Epworth Sleepiness Scale [7].

Rosales Mayor et al. [8] carried out a study to determine levels of fatigue and drowsiness in bus drivers. Rosales-Mayor et al. [8] used a validated questionnaire to evaluate sleep patterns, as well as the Epworth Sleepiness Scale. The questionnaires were applied to 100 
bus drivers of the male gender with average age $( \pm s)$ of $42.9 \pm 9.9$ years. The Body Mass Index showed obesity in $22 \%$ of drivers. The average time $( \pm s)$ as bus drivers was $13.7 \pm 9.7$ years. Ninetyeight drivers reported driving during the night shift, of which $66 \%$ worked 5 to 7 days per week on that shift. The drivers showed an average score $( \pm s$ ) of $7.1 \pm 3.9$ in the Epworth Sleepiness Scale. In addition, $13 \%$ of drivers indicated excessive sleepiness, and $17 \%$ blinking. Fifty-nine drivers reported having had an accident; or, having been at risk of being injured due to the fatigue [9].

Risco et al. [10] conducted a cross-sectional study to determine the prevalence of excessive sleepiness in bus drivers. Risco et al. [10] evaluated 434 drivers with ages between 18 and 71 years (average age, 35 years) using the Sleepiness Scale of Epworth.32 The authors showed excessive sleepiness in $32.7 \%$ of the drivers. Risco et al. [10] determined as predictive variables of excessive sleepiness at night shift $(p=0.02)$, habitual snoring $(p=0.04)$, depression ( $p=$ $0.003)$, anxiety $(p=0.001)$, and excessive consumption of alcoholic beverages $(p=0.04)$.

De Assis \& De Oliveira [11] evaluated 262 bus drivers in order to identify the risk factors associated with excessive sleepiness. The drivers had an average age $( \pm s)$ of $38.1 \pm 5.8$ years and were male. The average Body Mass Index was $26.8 \pm 3.5 \mathrm{Kg} / \mathrm{m}^{2}$ and an average neck circumference $( \pm \mathrm{s}$ ) was $40.4 \pm 2.5 \mathrm{~cm}$. In $28 \%$ of drivers were registered> 10 points in the Epworth Sleepiness Scale. In this regard, 48\% indicated excessive sleepiness when driving, and reported consuming tobacco (27\%), cola drinks (55\%), alcoholic beverages $(65 \%)$ and coffee $(88 \%)$ to stay alert when driving the bus. On the other hand, $48 \%$ of the drivers reported having accident when driving. Of these, $8 \%$ indicated that it was due to excessive sleepiness. The authors showed a significant association of the Body Mass Index and the Epworth Sleepiness Scale $(r=0.30, p=$ 0.04) [12].

Vennelle et al. [13] evaluated 677 bus drivers in Edinburgh to determine the frequency of daytime sleepiness and the frequency of accidents. Vennelle et al. [13] applied a validated questionnaire to the drivers, and the Epworth Sleepiness Scale. The drivers had a median age of 42 years, and 3.6\% were female. In addition, they determined a median Body Mass Index of $27 \mathrm{Kg} / \mathrm{m}^{2}$. Vennelle et al. [13] indicated that $11 \%$ of drivers reported slumber at least once a month while driving. 53\% reported having had an accident due to drowsiness. Drivers with scores $\geq 10$ on the Epworth Sleepiness Scale recorded a higher number of accidents $(p=0.027)$. Vennelle et al. [13] reported a frequency of SAOS corresponding to $20 \%$ of the drivers.

Rey de Castro et al. [14] applied a validated questionnaire in a total of 238 bus drivers to evaluate the association between excessive sleepiness and frequency of road traffic accidents. The average age of the surveyed drivers corresponded to 42.5 years and all were male. The average Body Mass Index $( \pm s)$ of the drivers was $29 \pm 4.4 \mathrm{Kg} / \mathrm{m}^{2}$. The drivers reported having an average $( \pm \mathrm{s})$ of $17.3 \pm 9.8$ years in work experience as bus drivers. Additionally, they indicated driving an average $( \pm s)$ of $7.9 \pm 2.5$ hours during the day, and $47 \%$ reported sleeping less than 7 hours per day. $80 \%$ of drivers indicated driving $>5$ hours during the day continuously. The perception of fatigue while driving was $56 \%$. Of the total number of drivers, $32 \%$ reported having blinked while driving. In addition, $81 \%$ of the drivers claimed to sleep in the trunk of the bus. To stay alert, $27 \%$ of the drivers reported applying water on their faces, $18 \%$ reported taking some fresh fruit, and 14\% reported opening the cabin window completely. Regarding the sleep pattern, $37 \%$ of the drivers reported snoring habitually. On the other hand, $45 \%$ of drivers indicated having had an accident; or, having been at risk of getting injured due to fatigue. This proportion showed a significant association only with the frequency of blinking and with the perception of driving fatigue [15].

Dalziel \& Job [16] conducted a study to identify the factors associated with sleepiness in taxi drivers, and their participation in traffic accidents. They evaluated 42 taxi drivers in a metropolitan area. The average driving time per week was 59 hours. The drivers worked nominally for 12-hour shifts; however, the duration of the work shift was modified according to the demand of the service, showing increases in peak hours as on the nights of the end of the shift week. The authors indicated that the number of traffic accidents was associated significantly but inversely proportional to the time for rest during the shift [17]. Drivers they showed an optimistic attitude towards their ability to drive and the feeling of drowsiness. It is important to point out that no chore reported having participated in a traffic accident due to drowsiness. The authors pointed out that the constantly changing conditions in taxi driving can cause fatigue. That is, the activities of driving a taxi (conversing with passengers, monitoring the dispatcher, finding a passage, determining the route of the trip) can be mentally demanding and therefore exhausting [18].

Charlton et al. [19] conducted a study to identify attitudes towards fatigue and sleepiness levels in 102 taxi drivers. $42 \%$ of drivers reported driving more than the recommended maximum of 11 hours in the previous 24 hours, and 39\% reported experiencing fatigue. The study showed the optimistic attitude to drive safely when fatigued, with only $2 \%$ of drivers considering drowsiness as a problem. The authors noted that this result increases the possibility that there is an up-regulation of the level of drowsiness in this driver [20].

Lam L T [21] evaluated traffic records related to accidents to determine environmental factors associated with mortality from traffic accidents and injuries to taxi drivers. They reviewed 7,923 records of taxi drivers involved in accidents, noting that $10 \%$ died or were injured. There was evidence of higher mortality and injuries in female drivers. In addition, they identified two 
risk factors associated with an increased frequency of accidents, including the night shift, and not carrying a passenger on board when the accident occurred [22].

Susanto et al. [23] evaluated 103 taxi drivers to determine the frequency and factors associated with OSAS. Susanto et al. [23] showed evidence of OSOS in $52.4 \%$ of drivers. Their results reported that the average BMI in taxi drivers with SAOS was $25.18 \mathrm{Kg} /$ $\mathrm{m}^{2} \pm 2.1$ compared to the average BMI in drivers without OSA that was $24.24 \mathrm{Kg} / \mathrm{m}^{2} \pm 1.3(\mathrm{p}=0.001)$. Likewise, when comparing both groups, significant differences were shown in the average body weight $(71.4 \mathrm{Kg} \pm 8.5$ vs. $65.8 \mathrm{Kg} \pm 5.7, \mathrm{p}<0.001)$, in the circumference of the neck $(38.5 \mathrm{~cm} \pm 2.5$ vs. $37.2 \mathrm{~cm} \pm 2.0, \mathrm{p}<0.001)$ and in the abdominal perimeter $(91.5 \mathrm{~cm} \pm 7.9$ vs. $86.5 \pm 5.5, \mathrm{p}<0.001)$. The symptoms that showed statistical difference between drivers with and without OSAS included habitual snoring (66.1\% vs. $33.9 \%$, $\mathrm{p}=0.003)$, feeling of not having slept well $(77.1 \%$ vs. $22.9 \%, \mathrm{p}=$ $0.001)$, drowsiness while driving $(73.3 \%$ vs. $26.7 \%, p=0.009)$ and headache ( $83.3 \%$ vs. $16.7 \%, p=0.001)$. The authors reported as risk factors associated with OSAS a higher BMI with an $\mathrm{OR}=60$ (95\% CI $=0.45-0.79, \mathrm{p}=0.001$ ), family history of habitual snoring with an $\mathrm{OR}=4.9(95 \% \mathrm{CI}=1.8-13, \mathrm{p}=0.002)$, and sleep duration less than 7 hours for a period of 24 hours with an OR= $5.1(95 \% \mathrm{CI}$ $=1.3-19.2, p=0.015$ ) [24].

Benaicha et al. [25] carried out a cross-sectional study in order to estimate the prevalence of fatigue in taxi drivers. They evaluated 300 male drivers who worked both in rural and urban areas. The average age of the drivers was $42.5 \pm 10$.8 years. The average BMI was $26.8 \pm 4.3 \mathrm{Kg} / \mathrm{m}^{2}$. The drivers reported $8.3 \pm 3.5$ years of experience as taxi drivers. Of all the drivers, $2.3 \%$ worked in the night shift, $57.1 \%$ in the morning shift, and $40.5 \%$ in both shifts. Benaicha et al. [25] reported an average score of $13.5 \pm 8.2$ in the Pichot Scale. The drivers reported sleeping an average of $6.7 \pm 1.4 \mathrm{~h}$ per day. A rate corresponding to $2.7 \pm 1.1$ accidents per year was recorded. The results of linear regression showed factors associated with fatigue at economic income $(p=0.017)$, cardiovascular disease $(p=0.001)$, smoking $(p=0.010)$, difficulties with partners $(p=0.002)$, regularity of sleep $(p=0.013)$ and drowsiness while driving $(p=0.002)$ [26]. Growing evidence points out that some sleep disorders may favour or exacerbate mood disturbances. They are also considered a high risk factor for the development of depression, bipolar disorder and suicide [27].

\section{Sleep Disorders, Ideation and Suicidal Behaviour}

Worldwide estimates indicate that 900,000 deaths per year occur due to suicide. Recent clinical and epidemiological studies indicate that sleep deprivation, insomnia and nightmares are significant factors for high risk of suicide. These factors are independent when controlling the influence derived from psychiatric co morbidities such as depression [28]. The National
Center for Mental Health Information in the United States of America recommended considering sleep disorders among the first ten warning signs for suicide risk [29].

In one study, Sabo et al. [30] evaluated the results of electrophysiological recordings in patients diagnosed with major depressive disorder and attempted suicide, and compared them with studies conducted in depressed patients but with no history of attempted suicide Sabo et al. [30] reported that brain activity during sleep, it showed longer latency time, and fewer delta-type waves in patients who had attempted suicid. On the other hand, Agargun et al. [31] evaluated patients with a history of attempted suicide, and evidenced a significant proportion of EEG records demonstrating lower latency and greater amount of REM sleep.

In a study conducted with monozygotic adolescents, it was shown that the association between sleep disorders with suicidal ideation persisted after controlling for genetic and environmental influences [32].

Suicidal ideation is defined as the existence of indifferent thoughts towards life and that can be associated with the elaboration of specific plans to take one's life [33]. Some electrophysiological record studies indicate that the decrease in sleep quality is associated with more suicide attempts. On the other hand, research suggests that alterations in chrono biological activity are associated with suicidal ideation, and point out that the majority of deaths due to suicide occur between midnight and 4:59 a.m. [34].

\section{Common Mechanisms between Sleep Disorders and Suicide Risk}

\section{Pessimism}

Studies refer to a high frequency of individuals with suicidal thoughts who additionally have pessimistic ideas. It is said that pessimistic ideas form a specific part of the so-called Pessimistic Cognition Process. This construct constitutes a different factor from what is usually understood as pessimism, and is demonstrated by psychometric studies [35].

\section{Impairment of executive function}

It is shown that insomnia and sleep deprivation constitute different conditions; however, they are characterized by a decrease in the amount of sleep an individual requires. A lower amount of sleep is associated with difficulty in making decisions; particularly those associated with finding solutions to everyday problems (cognitive dysfunction). It is said that the difficulty in the executive function varies according to the vulnerability of each individual, being able to consider suicide as the only probability or option [36].

It plays a significant role in both suicidal ideation and behavior and in sleep regulation. A high concentration of serotonin is demonstrated during the waking state, which decreases in slow 
wave sleep, and evidences its lower concentration during REM sleep. However, the association between serotonin and sleep is complex. Recent studies indicate that the release of serotonin during the waking state promotes homeostatic regulation over slow wave sleep. Thus, sleep deprivation and insomnia are associated with a serotonergic dysfunction at the level of the CNS, consisting of a decrease in its synthesis that, in turn, promotes the waking state. In several publications it is reported that these disorders increase the risk for suicide, because people with suicidal ideation and behaviour show decreased serotonin. Likewise, the modulation of executive function at the level of the prefrontal cortex is carried out by means of serotonin. Due to the above, the alteration of serotonergic mechanisms is considered a risk marker for suicide, violent impulsivity and a lower capacity for problem solving [37].

\section{Hyper vigilia}

Convergent lines of recent evidence point to primary insomnia as a condition of hypervigila. Several authors postulate that sleep deprivation causes hypothalamic-pituitary-adrenal (HHA) axis dysfunction. Activation of the HHA system results in secretion of hormones including corticotropin-releasing hormone, adrenocorticotropic hormone, and cortisol that promotes hypervigilia. It is shown that cortisol is a significant biological marker for the risk of suicide. Studies show a higher suicide risk associated with an evening increase in cortisol concentration prior to the onset of sleep. Some authors postulate that this increase could be due to the dysfunction of the HHA system due to insomnia and sleep deprivation. That is, the dysfunction in the HHA system causes a hypervigile state, and is a common feature between insomnia and sleep deprivation with suicidal behaviour. On the other hand, it is recently postulated that the association between insomnia and sleep deprivation with a high risk of suicide could be due to a lower concentration of hypothalamic peptides called "orexins". These peptides intervene in the regulation of sleep, appetite and waking state [38,39].

Circadian rhythm the association between insomnia and sleep deprivation with a higher risk of suicide, would suggest that a high number of suicides occur during the night. However, suicides between midnight and 8:00 a.m. are relatively infrequent. The frequency of suicides increases between 8:00 a.m. and noon. This is due to the fact that individuals with afternoon chronotype experience a greater feeling of discomfort during this time. In general terms, some people refer to being "early risers" or having a morning chronotype, and other individuals are described as "night owls" or evening cronotype. These concepts have been reinforced through studies with imaging techniques at the CNS level, in which variations in structures related to the sensation of affection are evidenced, and which agree with the chronotype of the individual $[40,41]$.
It remains to be determined whether the chronotype constitutes a high risk factor for suicide, per se. However, the morning schedule is associated with a lower level of aggressiveness, protection against major depressive disorder, and providing relief of symptomatology in major depression. On the other hand, at night time, there is a greater frequency of individuals who report having nightmares, difficulty falling asleep, poor sleep quality, fewer hours of sleep, and a well-established correlation with depression. In addition, the evening chronotype correlates with a greater degree of impulsivity and lethality of the suicidal method in contrast to morning-type individuals [42-44].

Choi et al. [45] carried out a study to evaluate the association between insomnia with suicidal ideation in 117 patients with OSAS, and showed correlation in limits of statistical significance. The correlation stopped showing statistical importance after controlling results according to the severity of the depressive symptoms. However, Choi et al. [45] reported a suicidal ideation rate in $20.5 \%$ of patients.

Recently, Edwards et al. [46] reported a significant decrease in the frequency of suicidal ideation in patients with OSAS, after three months of treatment with application of continuous positive pressure in the airway.

Chan et al. [47] evaluated a cohort composed of 253 patients with major depressive disorder. The average age of the patients was 50.8 years (86.6\% women). Chan et al. [47] formed three groups of patients according to their chronotype including morning (62), intermediate (142) and evening (49). They reported a frequency of insomnia in $19.4 \%, 35.2 \%$, and $45.4 \%$, respectively. Patients were evaluated using the Hamilton questionnaire to determine the severity of the depressive disorder, and recorded average scores of $8.4 \pm 5.3$ points in patients with morning chronotype, $8.5 \pm 6.4$ in the intermediate chronotype group, and $12.9 \pm 6.9$ in chronotype patients evening. In addition, they reported a higher number of suicide attempts in the afternoon chronotype group (49\%) compared to patients with morning and intermediate chronotypes (32.3\% and $18.7 \%$, respectively) [48].

Dell'Osso et al. [49] when prospectively evaluated 65 adult patients (33 men, 32 women), with average age ( \pm s) of $45 \pm 14.8$ years. All patients were diagnosed with Post-Traumatic Stress according to DSM-5. Of the total number of patients, $58.4 \%$ reported having a part-time or full-time job, and the rest indicated that they were unemployed or retired. 56\% referred marital status or married or in free union. The patients were evaluated by applying the MOODS-SR questionnaire to determine the frequency of depression, mania, cognition and characteristics in circadian rhythmicity. Dell'Osso et al. [49] determined the existence of variations in circadian rhythmicity associated with the sensation 
of energy, appetite, sexual activity, sleep pattern, and in symptoms including headache, dry mouth, and constipation; as well as in the sensation of heat and cold. The authors evaluated the frequency of suicidal ideation, and reported a significant association between circadian rhythmicity with suicidal ideation $(\mathrm{p}<0.001)$; in addition, Dell'Osso et al [49] indicated that circadian variations in appetite were the main risk factor for attempted suicide with an $\mathrm{OR}=2.09$ (95\% CI= $1.1-3.8)$.

Yoon et al. [50] analyzed the results of the "National Survey on Health and Nutrition in Korea" to determine the association between the risk of suicide and sleep deprivation. They evaluated the information on 12,076 participants in the survey 7,164 men, 4,912 women) who were aged between 18 and 60 years. Yoon et al. [50] showed significantly higher frequency of suicidal ideation in participants who reported sleeping $\leq 5$ hours / day, compared to participants who reported sleeping 6 - 9 hours / day $(16.9 \%$ vs. $10.7 \%, \mathrm{p}<0.001)$. They also indicated that women had a significantly higher frequency of suicidal ideation with respect to male participants $(16.8 \%$ vs. $7.89 \%, \mathrm{p}<0.05)$. On the other hand, the authors showed that working a quantity $\geq 60$ hours / week was a significant risk factor for suicidal ideation with an OR $=1.34(95 \%$ $\mathrm{CI}=1.15$ - 1.57).

Estimates worldwide indicate that $15 \%$ of the total economically active population works in "shift work", which include schedules different from traditional working hours between 9:00 a.m. and 17:00 p.m. [51]. This schedule includes work shifts with evening, night, and early morning hours and with schedule rotation [52]. The basic physiological principles support the incompatibility that arises between shift work and the biological characteristics inherent to the circadian rhythm. In this regard, in some studies a certain adaptation in the sleep-wake cycle is related to changes in circadian rhythm; however, they point out that any adaptation is limited since the sleep-wake cycle comprises only one circadian cycle among the various organic functions that show this rhythmicity [53,54].

Sleep disturbances occur more frequently in work at night and at dawn. In these working hours, the total sleep time decreases between one to four hours, and also decreases its quality [55]. Shift work is often associated with excessive sleepiness that interferes with alertness and cognitive functioning. This has repercussions on the execution of work activities, as well as on aspects related to job security, even in spite of optimizing environmental conditions [56]. In vulnerable individuals, the alteration in the circadian rhythm that results from shift work increases the frequency of mood disorders. In this regard, several studies indicate that the frequency of these disorders is associated with the time of exposure to the modification of circadian rhythmicity [57].

Recent studies indicate that the performance of people with excessive sleepiness in certain occupations with shift schedules may have repercussions on third parties; in particular, in police organizations, health care areas, and emergency services [58]. Many studies show a high frequency of taxi drivers with excessive sleepiness during their work performance. In addition, they indicate that drowsiness is a significant cause of traffic accidents. Drowsiness and sleep deprivation that verifies a significant proportion of taxi drivers are due to changes in the circadian rhythm and also due to the high frequency of OSAS Excessive sleepiness and sleep deprivation are considered high risk factors for the development of sleep. Suicidal ideation and behaviour.

\section{References}

1. Lim SM, Chia SE (2015) The prevalence of fatigue and associated health and safety risk factors among taxi drivers in Singapore. Singapore Med J 56(2): 92-97.

2. Hale L (2005) Who has time to sleep? J Pub Health 27(2): 205-211.

3. Lack LC, Gradisar M, Van Someren EJW, Wright HR, Lushington K (2008) The relationship between insomnia and body temperatures. Sleep Med Rev 12(4): 307-317.

4. Muzet A (2007) Environmental noise, sleep and health. Sleep Med Rev 11(2): 135-142.

5. Rasch B, Born J (2013) About sleep's role in memory. Physiol Rev 93(2): 681-766.

6. Caso A, Rey de Castro J, Rosales-Mayor E (2017) Hábitos del sueño y accidentes de tránsito en conductores de ómnibus interprovincial de Arequipa, Perú. Rev Peru Med Exp Salud Pública 31(4): 707-711.

7. Lewis PA, Durrant SJ (2011) Overlapping memory replay during sleep builds cognitive schemata. Trends Cogn Sci 15(8): 343-351.

8. Rosales-Mayor E, Egoavil M, Durand I, Montes N, Flores R, et al. (2009) Accidentes de carretera y su relación con cansancio y somnolencia en conductores de ómnibus. Rev Med Hered 20(2): 48-55.

9. Leger D, Poursain B, Neubauer D, Uchiyama M (2008) An international survey of sleeping problems in the general population. Curr Med Res Opin 24(1): 307-317.

10. Risco J, Ruiz P, Juárez A, Ramos M, Salmavides F, et al. (2013) Excessive sleepiness prevalence in public transportation drivers of a developing country. Traffic Inj Prev 14(2): 145-149.

11. De Assis Viegas C, De Oliverira HW (2006) Prevalence of risk factors for obstructive sleep apnea syndrome in interstate bus drivers. J Bras Pneumol 32(2): 144-149.

12. Van Cauter E, Leproult R, Plat L (2000) Age-related changes in slow wave sleep and REM sleep and relationship with growth hormone and cortisol levels in healthy men. JAMA 284(7): 861-868.

13. Vennelle M, Engleman HM, Douglas NJ (2010) Sleepiness and sleeprelated accidents in commercial bus drivers. Sleep Breath 14(1): 39-42.

14. Rey de Castro J, Rosales E. Cansancio y (2010) somnolencia durante el desempeño laboral de los conductores interprovinciales: Experiencia Peruana y planteamiento de propuestas. Rev Peru Med Exp Salud Pública 27(2): 237-42.

15. Fido A, Ghali A (2008) Detrimental effects of variable work shifts on quality of sleep, general health and work performance. Med Princ Pract 17(6): 453-457.

16. Dalziel J, Job R (1977) Motor vehicle accidents, fatigue and optimism in taxi drivers. Accid Anal Prev 29(4): 489-494. 
17. Wright KP, Drake AL, Frey DJ, et al. (2015) Influence of sleep deprivation and circadian misalignment on cortisol, inflammatory markers, and cytokine balance. Brain Behav Immun 47: 24-34.

18. Borbély AA, Daan S, Wirz JA, Deboer T (2016) The two process model of sleep regulation: A reappraisal. J Sleep Res 25(2): 131-143.

19. Charlton S, Baas P, Alley B (2003) Analysis of fatigue levels in New Zealand taxi and local route truck drivers. Hamilton: Land Transport Safety Associations.

20. Dillon HR, Lichstein KL, Dautovich ND, Taylor DJ, Riedel BW, et al. (2015) Variability in self-reported normal sleep across the adult age span. Journals of Gerontology, Series B: Psychological Sciences and Social Sciences 70(1): 46-56.

21. Lam LT (2004) Environmental factors associated with crash-related mortality and injury among taxi drivers in New South Wales, Australia. Accid Anal Preven 36(5): 905-908.

22. Durmer JS, Dinges DF (2005) Neurocognitive consequences of sleep deprivation. Semin Neurology 25(1): 117-129.

23. Susanto AD, Hisyam B, Maurits LS, Yunus F (2015) Clinical symptoms and related factors of obstructive sleep apnea among overweight and obese taxi drivers. Med J Indones 24(4): 206-214.

24. Kucharczyk ER, Morgan K, Hall AP (2012) The occupational impact of sleep quality and insomnia symptoms. Sleep Med Rev 16(6): 547-559.

25. Benaicha N, Diarra A, Diakite OD, Oussamne SY, Najdi A, et al. (2016) Moroccan Taxi Drivers Fatigue Using Pichot Questionnaire: A CrossSectional Survey. J Life Science 10(2): 114-120.

26. Wright KP, Bogan RK, Wyatt JK. Shift work and the assessment and management of shift work disorder. Sleep Med Rev 17(1): 41-54.

27. Aidman E, Chadunow C, Johnson K, Reece J. Real-time driver drowsiness feedbackimproves driver alertness and self-reported driving importance. Accid Anal Prev 81: 8-13.

28. Philip P, Sagaspe P, Lagarde E, Leger D, Ohayon MM, et al. (2010) Sleep disorders and accidental risk in a large group of regular registered highway drivers. Sleep Med 11(10): 973-979.

29. Colvin LJ, Collop NA (2016) Commercial motor vehicle driver obstructive sleep apnea screening and treatment in the United States: an update and recommendation overview. J ClinSleepMed 12(1): 113-25.

30. Sabo E, Reynolds CF, Kupfer DJ, Berman SR (1991) Sleep, depression, and suicide. Psychiatry Res 36(3): 265-7731.

31. Agargun MY, Cartwright R (2003) REM sleep, dream variables and suicidality in depressed patients. Psychiatry Res 119: 33(1-2)-932.

32. De Assis-Viegas C, De Oliverira HW (2006) Prevalence of risk factors for obstructive sleep apnea syndrome in interstate bus drivers. J Bras Pneumol 32(2): 144-149.

33. Bernert RA, Joiner TE (2007) Sleep disturbances and suicide risk: A review of the literature. Neuropsychiatric Dis Treat 3(6): 735-743.

34. Matamura M, Tochigi M, Usami S, et al. (2014) Associations between sleep habits and mental health status and suicidality in a longitudinal survey of monozygotic twin adolescents. J Sleep Res 23: 290-294.

35. McCall WV, Black CG (2013) The link between suicide and insomnia: Theoretical mechanisms. Curr Psychiatry Rep 15(9): 389.

36. Kohyama J (2011) Sleep, serotonin, and suicide in Japan. J Physiol Anthropol 30(1): 1-8.

37. Clow A, Hucklebridge F, Stalder T, Evans P, Thorn L (2010) The cortisol awakening response: More than a measure of HPA axis function. Neurosci Biobehav Rev 35(1): 97-103.
38. Verkevisser M, Van Dongen HP, Kerkhof GA (2005) Physiologic indexes in chronic insomnia during a constant routine: Evidence for general hyperarousal? Sleep 28(12): 1588-1596.

39. Pigeon WR, Titus CE, Bishop TM (2016) The relationship of suicidal thoughts and behaviors to sleep disturbance: A review of recent findings. Curr Sleep Medicine Rep 2(4): 241-250.

40. Potter G, Arendt DJ, Cade JE, Grant PJ, Hardie LJ (2016) Circadian rhythm and sleep disruption: Causes, metabolic consequences, and countermeasures. Endocr Rev 2016; 37(6): 584-608.

41. Heo YS, Chang SJ, Park SG, Leem JH, Jeon SH, et al. (2013) Association between workplace risk factor exposure and sleep disturbance: Analysis of the $2^{\text {nd }}$ Korean working conditions survey. Ann Occup Environ Med 25: 41 .

42. Ogilvie R, Wilkinson R (1984) The detection of sleep onset: Behavioral and physiological convergence. Psychophysiology 21(5): 510-520.

43. Freedman RR (1986) EEG power spectra in sleep-onset insomnia. Electroencephalogr Clin Neurophysiol 63(5): 408-413.

44. Lesch D, Spire P (1990) Handbook of sleep disorders. Clinical Electroencephalography New York, pp. 13-32.

45. Choi SJ, Joo EY, Lee YJ, Hong SB (2015) Suicidal ideation and insomnia symptoms in subjects with obstructive sleep apnea syndrome. Sleep Med 16(9): 1146-1150

46. Edwards C, Mukherjee S, Simpson L, Palmer LJ, Almeida OP, et al. (2015) Depressive symptoms before and after treatment of obstructive sleep apnea in men and women. J Clin Sleep Med 11(9): 1029-1038.

47. Chan JWY, Lam SP, Li SX, Yu MWM, Chan NY et al. (2014) Eveningness and insomnia: Independent risk factors of nonremission in major depressive disorder. Sleep 37(5): 911-917.

48. Gonnissen HK, Rutters F, Mazuy C, Martens EA, Adam TC, et al. (2012) Effect of a phase advance and phase delay of the $24 \mathrm{~h}$ cycle on energy metabolism, appetite, and related hormones. Am J Clin Nutr 96(4): 689697.

49. Dell'Osso L, Massimetti G, Conversano C, Bertelloni CA, Carta MG, et al. (2014) Alterations in circadian/seasonal rhythms and vegetative functions related to suicidality in DSM-5 PTSD. BMC Psychiatry 14(1): 352 .

50. Yoon J-H, Jung PK, Roh J, Seok H, Won JU (2015) Relationship between long working hours and suicidal thoughts: Nationwide data from the $4^{\text {th }}$ and $5^{\text {th }}$ Korean National Health and Nutrition Examination Survey. PLoS ONE 10(6): e0129142.

51. Arendt J (2010) Shift work: coping with the biological clock. Occup Med 60(1): 10-20.

52. Woo JM, Postolache TT (2008) The impact of work environment on mood disorders and suicide: Evidence and implications. Int J Disabil Hum Dev 7(2): 185-200.

53. Richter K, Acker J, Adam S, Niklewski G (2016) Prevention of fatigue and insomnia in shift workers: A review of non-pharmacological measures. EPMA J 7: 16

54. Sookoian S, Gemma C, Gianotti TF, Burgueño A, Castaño G, et al. (2008) Genetic variants of clock transcription factor are associated with individual susceptibility to obesity. Am J ClinNutr 87(6): 1606-1615.

55. Peppard PE, Young T, Barnet JH, Palta M, Hagen EW, et al. (2013) Increased prevalence of sleep disordered breathing in adults. Am J Epidemiol 177(9): 1006-1014.

56. Uehli K, Mehta AJ, Miedinger D, Hug K, Schindler C, et al. Sleep problems and work injuries: A systematic review and meta-analysis. Sleep Med $\operatorname{Rev} 18(1): 61-73$. 
57. Stevenson MR, Elkington J, Sharwood L, Meuleners L, Ivers R, et al. (2014) The role of sleepiness, sleep disorders, and the work environment on heavy-vehicle crashes in two Australian States. Am J Epidemiol 179(5): 594-601.
58. Ballard ED, VandeVoort JL, Bernert RA, Luckenbaugh DA, Richards EM, et al. Nocturnal wakefulness is associated with next-day suicidal ideation in major depression and bipolar disorder. J Clin Psychiatry 77(6): 825831.

\section{(c) This work is licensed under Creative}

To Submit Your Article Click Here:

Submit Article

DOI: $10.32474 / 0 J N B D .2018 .01 .000113$

Online Journal of Neurology
and Brain Disorders
Assets of Publishing with us

